\title{
Role of 14-Bp HLA-G, INDEL Polymorphism in Recurrent Miscarriage
}

\author{
Fateme Afkhami ${ }^{1}$, Neda Yazdani ${ }^{1}$, Mahmoud Shekari Khaniani ${ }^{1}$ \& Sima Mansoori Derakhshan ${ }^{1}$ \\ ${ }^{1}$ Medical Genetic Department, Medical Faculty, Tabriz University of Medical Sciences, Tabriz, Iran \\ Correspondence: Sima Mansoori Derakhshan, Medical Genetic Department, Medical Faculty, Tabriz University \\ of Medical Sciences, Tabriz, Iran. Tel/Fax: 98-41-3337-1587. E-mail: mderakhshan2002@gmail.com
}

Received: December 21, 2015

Accepted: February 28, 2016 Online Published: April 29, 2016

doi:10.5539/gjhs.v8n12p45

URL: http://dx.doi.org/10.5539/gjhs.v8n12p45

\begin{abstract}
Mothers and their fetuses are hereditarily unlike. Surprisingly, no less than $50 \%$ human pregnancies reach full term despite the tendency of the immune system to eliminate of non-self units. Reduction of adaptive maternal immune answer, which is planned to reject strange factors, is essential for a pregnancy to reach full term. However, approximately 5\% couples trying to conceive experience 2 recurrent miscarriages (RMs).

$H L A-G$, which is produced by the external trophectoderm layer and has unique biological features, is involved in the implantation and maintenance of fetus. Serum $H L A-G$ levels are correlated with the risk of RM. Recent studies indicate that a 14-bp HLA-G, INDEL polymorphism decreases the level of $H L A-G$ mRNA, which in turn decreases the amount of $H L A-G$ produced. An understanding of gene parameter and the function of polymorphic sites in the functioning of $H L A-G$ products may enable the development of approaches targeting $H L A-G$ for more detail of causes of RM.
\end{abstract}

Keywords: $H L A-G$, insertion-deletion, miscarriage, polymorphism, 3' UTR

\section{Brief Overview on Miscarriage}

Miscarriage is the accepted formal name for early pregnancy loss before fetal viability. The term sporadic abortion (SAB) is used to describe pregnancy loss before 20 weeks of gestation. Recurrent miscarriage (RM) refers to $\geq 3$ consecutive SABs (Ford, 2009). Incidence of SAB is estimated to be $15 \%$ of all conceptions and varies significantly according to age (Ford \& Schust, 2009). Compared with SAB, the prevalence of RM is considerably low and varies between $0.8 \%$ and $3 \%$ (Larsen et al., 2013). RM may occur because of various reasons; however, not all of these reasons have been identified. RM is directly associated with parental chromosomal anomalies (approximately 4\%), maternal thrombophilic disorders (40\%), and structural uterine anomalies (19.3\%) and is indirectly associated with maternal immune dysfunction (3\%-5\%) and endocrine abnormalities (17\%-20\%). However, at least 50\% cases of RM do not show variations in any practical diagnostic test and are thinked idiopathic or unexplained cause (Ford \& Schust, 2009). Most cases of unexplained RM are considered to be caused by immunological rejection of the embryo by the immune system of the mother (Matter \& Sharif, 2013).

Risk of miscarriage is the most common complication of early pregnancy in humans. Therefore, women who experience 2 consecutive pregnancy losses without previous live births should be examined thoroughly (Ford \& Schust, 2009). Identifying the cause of miscarriage may help prevent it from happening again during future pregnancies. In recent years, advancements in the field of immunogenetic analysis and improved perception of implantation have provided new approaches into the origin of RM and have opened new possibilities for research on its prevention and also treatment.

\subsection{Human Leukocyte Antigen-G (HLA-G)}

Genes that control implantation, fetal-placental growth, and adaptation of mother for pregnancy are mainly expressed by the placenta or the fetus. Human leukocyte antigens (HLAs), which are the most important determinants of allograft rejection, have been extensively studied in the framework of immune tolerance during pregnancy (Mallia et al., 2012). A non-classical $H L A$ class I molecule, $H L A-G$, plays a tolerogenic part at the maternal-fetal interface and keeps the fetus from devastation by the mother's immune system. 


\subsection{HLA-G Gene}

$H L A-G$ is a high-density $3.6-\mathrm{Mb}$ gene area situated in the $6 \mathrm{p} 21.3$ chromosome region, which includes over than 200 genes (Castelli et al., 2011). HLA-G encodes non-classical class Ib $H L A$ particle and is placed between $H L A-A$ and $H L A-F$ (Figure 1A). $H L A-G$ is a non-classical molecule since it varies from classical HLA class I molecules with respect to its genetic variety, structure, expression, and functions. Some remarkable differences between $H L A$ class IA molecules and $H L A-G$ are as follows:

1) $H L A$ Ia molecules are extremely polymorphic, with many alleles, while $H L A-G$ has few variants.(Hunt, Petroff et al. 2005)

2) $H L A$ class Ia molecules are expressed on nearly every nucleated cells, whereas $H L A-G$ is expressed in the tissue- or organ-specific or conditional manner (Hunt \& Langat, 2009).

3) $H L A-G$ is involved in immune modulation and not in antigen presentation, on the opposite to the classical $H L A$ class Ia molecules (Veit et al., 2012).

4) $H L A-G$ has a unique promoter region, which is not observed in other $H L A$-encoding genes.

$H L A-G$ contains seven introns and eight exons, which code the heavy chain of the molecule. Exon one encodes a peptide signal while exons two, three, and four encode extracellular $\alpha 1, \alpha 2$, and $\alpha 3$ domains, correspondingly. Exons five and seven encode the transmembrane and cytoplasmic domains, respectively, of the heavy chain. Exon seven is at all times absent in the mature mRNA because of a stop codon in exon six. Exon eight does not undergo translation (Figure 1) (Foroni et al., 2014).

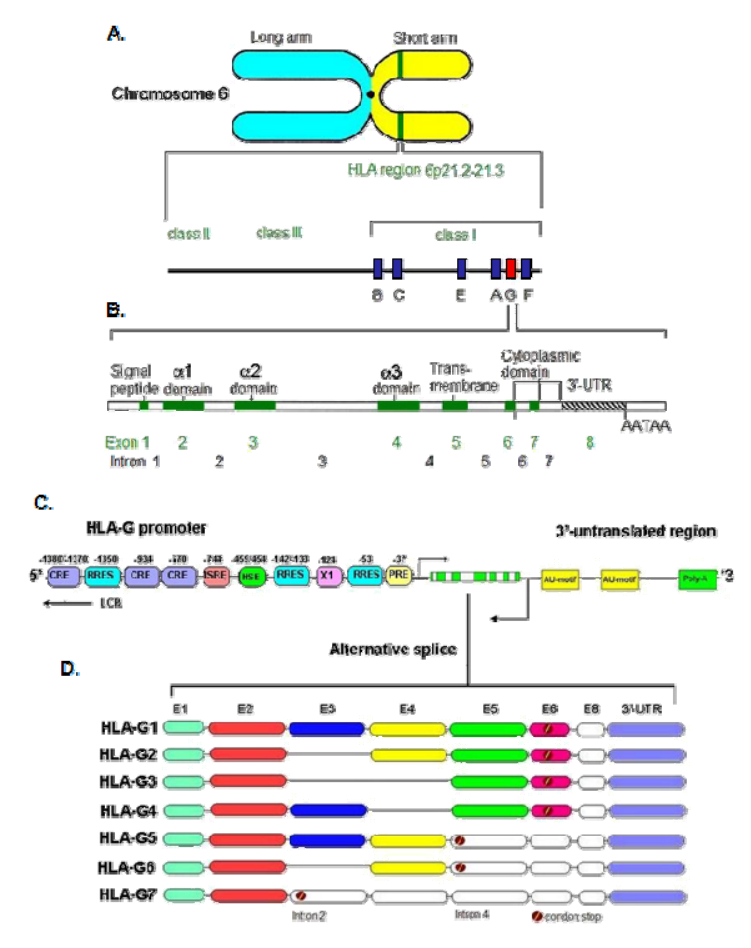

Figure 1. The human leukocyte antigen-G (HLA-G) gene and transcription

$H L A-G$ gene location. B.HLA-G gene structure consisting of 7 introns (white color) and 8 exons (green color). C. $H L A-G$ gene promoter exhibiting regulatory elements to regulate $H L A-G$ gene transcription and 3'-UTR of the $H L A-G$ gene exhibiting several regulatory elements including AU-rich motifs and a Poly-A signal to influence mRNA stability, turnover, mobility and splicing pattern. CRE stands for cAMP responsive element, RRES for ras response elements, ISRE for interferon-sensitive response element, HSE for heat shock response element, PRE for progesterone response element, and $\mathrm{X} 1$ for $\mathrm{X} 1$ box.D. $H L A-G$ primary transcript can be spliced into 7 alternative mRNAs ranging from $H L A-\mathrm{G} 1$ to $-\mathrm{G} 7$. 


\subsection{HLA-G Transcript}

The promoter elements of classical $H L A$-encoding genes are placed within 220-bp upstream of the start codon, ATG. In contrast, the promoter parts of $H L A-G$ are set in an area that covers $\sim 1.5-\mathrm{kb}$ upstream from its ATG codon (Veit et al., 2010). Many usual HLA promoter elements are deleted or modified in the HLA-G promoter state, thus making $H L A-G$ indifferent to classical HLA stimulators such asIRF1, CIITA, and NF- $\mathrm{KB}$. Another remarkable feature of the promoter is its high variability (Veit et al., 2012). The 3' UTR of HLA-G transcript contains a number of regulatory aspects, as well as AU-rich motifs and a poly-A signal to control its mobility, stability, turnover, and pattern of splicing (Lynge et al., 2014). In silico analysis of this section has identified several supposed microRNA-binding sites that may control $H L A-G$ expression depending on the haplotype or biological background (Donadi et al., 2011).

The construction of $H L A-G$ is homologous to that of genes encoding $H L A$ class IA molecules. However, the primary $H L A-G$ transcript be capable of be spliced into seven alternative mRNAs (Figure 1-D). HLA-G1 is a full-length molecule, $H L A-G 2$ not has exon three, $H L A-G 3$ not has exons three and four, and $H L A-G 4$ not has exon four. $H L A-G 1$ to $H L A-G 4$ contains the transmembrane and cytoplasmic domains that encoded by exons 5 and 6 , respectively so they are membrane-bound molecules. $H L A-G 5$ is like to $H L A-G 1$ but contains intron four, $H L A-G 6$ lacks exon three but contains intron four, and $H L A-G 7$ lacks exon three, however contains intron two. HLA-G5 and HLA-G6 are soluble proteins because theycontain intron four which contains a premature stops codon that prevents the translation of the transmembrane and cytoplasmic domains.

Under normal conditions, most cells and tissues show a basal rank of $H L A-G$ transcription. However, translation of the HLA-G transcript occurs only in trophoblasts at the fetal-maternal interface and in cornea, thymic epithelial cells, nail matrix, pancreatic cells, mesenchymal stem cells, erythroid and endothelial precursors in adults (Amodio \& Gregori, 2012).

\subsection{HLA-G Proteins}

$H L A-G$ has 7 isoforms created by alternative splicing of the primary transcript. Of these, 4 isoforms (HLA-G1 to G4) are membrane bound and 3 isoforms ( $H L A-G 5$ to $G 7$ ) are soluble. A full-length molecule, $H L A-G 1$, is the lone isoform to be expressed on the cell surface. Membrane-bound $H L A-G$ isoforms and soluble perform comparable functions (Amodio \& Gregori, 2012; Klitkou et al., 2015).

$H L A-G$ has 2 single cysteine residues in position 42 of the $\alpha 1$ domain and position 147 of the $\alpha 2$ domain. $H L A-G$ uses these cysteines to undergo dimerization by forming intramolecular disulfide bonds (Carosella et al., 2011; Campbell et al., 2012). These residues allow HLA-G to form a number of atypical forms in addition to the usual heterotrimer. HLA-G associates with B2M, which binds to all classical HLA class I molecules, to form a disulfide-linked B2M-associated dimer. Apps et al. (Apps et al., 2007). Showed that noteworthy levels of B2M-associated $H L A-G$ dimmers were expressed on the surface of normal first trimester trophoblasts. Only $H L A-G 1$ and $H L A-G 5$ associate with B2M through their light chain, whereas the other 3 isoforms (HLA-G2, G3, and $G 4$ ) do not.

\section{Expression}

$H L A-G$ is the major $H L A$ molecule expressed at the fetal-maternal interface by fetal tissues (Matter \& Sharif, 2013). As stated, $H L A-G$ expression is generally controlled at the transcriptional stage by its unique promoter element and at the post-transcriptional stage by alternative splicing, mRNA stability, translation, and protein transport to the cell surface (Moreau et al., 2009). Several immune modifiers alter $H L A-G$ expression, such as anti-inflammatory cytokines, transforming growth factor- $\beta$, and granulocyte colony-stimulating factor. As well as cytokines, some hormones such as glucocorticoids and progesterone boost the secretion of both HLA-G5 and $H L A-G 6$ by trophoblasts (Amodio \& Gregori, 2012).

\subsection{HLA-G Regulation and Polymorphism}

Studies performed thus far point out that the level of soluble $H L A-G$ in plasma is related to $H L A-G$ polymorphism (Hviid, 2006). Thus far, upon on 72 single nucleotide polymorphisms detected in exon one and intron six, $44 H L A-G$ alleles have been identified. Nucleotide variation in the coding region of $H L A-G$ is equally allocated across exons two, three, and four and in introns (Donadi et al., 2011). On the contrary to the coding region, the promoter and 3' UTR of $H L A-G$ show a high degree of variability and genetic polymorphism. In addition, nearly all polymorphisms in $H L A-G$ do not change the amino acid sequence of the corresponding protein. However, only some of these polymorphisms are expected to alter the secondary structure of the heavy chain. One of these polymorphisms is the insertion or deletion of a 14-bp nucleotide (5'-ATTTGTTCATGCCT- $3^{\prime}$ ) in the $3^{\prime}$ UTR of the gene (Martelli-Palomino et al., 2013). Polymorphic location in the $3^{\prime}$ UTR are posed in 
numerous haplotypes; therefore, their effect seems to occur simultaneously (Castelli et al., 2010).

Serum HLA-G levels are associated with a risk of RM. Recent studies indicate that insertion of this 14-bp fragment is associated with reduced levels of $H L A-G$ mRNA (Torres et al., 2009; Enghelabifar et al., 2014), which in turn decreases the level of $H L A-G$ produced. Several studies have examined the correlation of this 14-bp INDEL polymorphism with the risk of RM. However, these studies have provided controversial results (Fan et al., 2014). Several studies have reported more homozygotes for the 14-bp INS sequence among RM women than normal fertile women. However, this correlation has not been reported in some studies (Hviid et al., 2002; Yan et al., 2006). Other studies have observed an increased number of heterozygous (Tripathi et al., 2004; Xue et al., 2007; Afkhami et al., 2014). However, some other studies have reported no correlation (Sipak-Szmigiel et al., 2008). These varied results are perhaps because of the differences in the allocation of the polymorphism in different ethnic groups and potential linkage disequilibrium with other $H L A$ variation. In different populations, the polymorphic sites in the 3' UTR are organized into several haplotypes, with each of them being associated with group or a single of promoter region and coding polymorphisms, thus form extended $H L A-G$ haplotypes that result in altered expression of $H L A-G$ mRNA and thus protein isoforms (Kolte et al., 2010). The14-bp INDELpolymorphism is suggested to perform the following functions:

1) Transcripts containing the 14-bp fragment may undergo an additional splicing step in which this sequence may act as a cryptic branch point and result in the alternative splicing of $H L A-G$ mRNA to remove 92 bases from this region (Haddad et al. 2011). Deletion of this sequence may affect mRNA stability. However,the ratio of -92and +92 -bp transcripts may vary based on the existence of the 14-bp fragment in the primary transcript and existence of other polymorphisms that are in linkage disequilibrium with this 14-bp fragment (Donadi et al., 2011).

2) The mRNA stability may also be affected by AU-rich elements in the $3^{\prime}$ UTR. This AU-rich element contains $\geq 1$ copies of AUUUA pentamer and assist in mRNA degradation. Because the initial pentameric AUUUG sequence of the 14-bp fragment has an AU pentamer-like effect, it may be engaged in the deadenylation and decay of HLA-G mRNA (Martelli-Palomino et al., 2013). However, it is unclear whether the 14-bp INDEL polymorphism directly results in the observed differences in the expression of $H L A-G$ mRNA or whether a polymorphism in the $H L A-G 5^{\prime}$ untranslated regulatory region is in linkage disequilibrium with the 14-bp polymorphism.

3) Few haplotypes such as $\mathrm{G}^{*} 01013(+14 \mathrm{bp})$ and $\mathrm{G}^{*} 0105 \mathrm{~N}(+14 \mathrm{bp})$ are known as low secretor haplotypes. High-secretor $H L A-G$ haplotypes such as $\mathrm{G}^{*} 01041$ (-14 bp) are related with high plasma levels of soluble $H L A-G$. The dominant effect of low secretor haplotypes (+14 bp) on high secretor haplotypes $(-14 \mathrm{bp})$ in the heterozygote reduces the amount of soluble $H L A-G$ produced (Tripathi et al., 2004). However, advanced studies are needed to clarify the precise biological mechanism underlying the principal effect of low secretor haplotypes on high secretor haplotypes.(4) Interestingly, the 14-bp polymorphism lies in a region that is a supposed binding site for many microRNAs, and microRNA binding is also postulated to control $H L A-G$ expression (Veit \& Chies, 2009). Results of basic studies indicate that the 14-bp fragment, which remains in an open configuration after mRNA folding, is a target of specific microRNAs. In silico structural studies on $H L A-G$ mRNA and promoter region suggest that modifications in the secondary structure of $H L A-G$ mRNA may influence its stability and accessibility to microRNAs (Wang et al., 2012). Nevertheless, assessment of the net effect of microRNAs on $H L A-G$ expression is difficult because microRNA profiles vary substantially among different tissues and biological states (Veit et al., 2012). In addition, several recent studies have suggested that aberrant or reduced $H L A-G$ expression is related with complications during pregnancy.

\subsection{HLA-G in Pregnancy}

$H L A-G$ expression was first described in the extravillous trophoblasts (EVTs) of the placenta (Hunt \& Langat, 2009). Therefore, initial studies on this molecule investigated its role as a major determinant of allograft rejection and immune tolerance during pregnancy (Mallia et al., 2012).

For successful implantation and safety against maternal immune cells, embryos express high levels of solvable $H L A-G$ (Picard et al., 2013). Studies have proved that during normal pregnancy, primary villous trophoblasts are $H L A$ null, while EVTs express $H L A-C, H L A-E$, and $H L A-G$ but not $H L A-A, H L A-B$, and $H L A-D R$ (Apps et al., 2011). Another study on $H L A-G$ and embryo implantation or miscarriage characterized $H L A-G$ expression in preimplantation embryos and human embryonic stem cells (Verloes et al., 2011).

$H L A-G$ is necessary in the male reproductive system to prevent the recognition of sperm cells as antigens and for the implantation process in seminal plasma (Larsen et al., 2011). HLA-G expression pattern, which originates from the father, blastocyst/embryo, mother, and trophoblasts, is unique among $H L A$-encoding genes and indicates that $H L A-G$ may be engaged in interactions that are vital for creating and continuing pregnancy (Warner et al., 2008). 
Soluble $H L A-G$ secreted by uterine lymphocytes in the decidual tissues and trophoblasts plays a key role in increasing the immunotolerance of blastocyst (Rico-Rosillo \& Vega-Robledo, 2012). Various recent studies have focused on the possible role of $H L A-G$ polymorphism in maternal tolerance to the developing fetus. Some studies have shown that maternal serum level of soluble $H L A-G$ is low (Zhao et al., 2009). During pregnancy failure and that a relationship exists between low level of soluble $H L A-G$ and the 14-bp polymorphism (Tripathi et al., 2004).

\subsection{Immune Mechanism of $H L A-G$}

Restricted $H L A-G$ expression is considered to offer immunoprotection to the semi-allogeneic embryo, and had suppressive effects on CD4+and CD8+T cells, B lymphocytes and antigen presenting cells such as macrophages and dendritic cells, and particularly from decidual NK (dNK) cells, which during early pregnancy, are the main lymphocytes at the fetal-maternal interface (Fan et al., 2014). Majority of dNK cells are CD56+NK cells that are dissimilar from peripheral blood NK cells (Apps et al., 2011).

$H L A-G$ inhibits the cytolytic activities of both NK cells and cytotoxic T cells, alloproliferative responses of CD4+T cells, ongoing proliferation of T lymphocytes and NK cells, and maturation of dendritic cells. (2012) In addition, in vitro studies point out that soluble isoforms of $H L A-G$ (HLA-G1 and G5) stimulate apoptosis of activated NK cells ,and endothelial cells, and alloreactive cytotoxic T cells (Alegre et al., 2014).

In general, regulatory cells including subpopulations of presenting cells (APC), CD8 T cells, and CD4 T, by interacting with $H L A-G$ modulate immune responses and promote immune tolerance (Carosella et al., 2011). $H L A-G$ exerts immunoin hibitory effect by binding to inhibitory receptors such as ILT2, ILT4, and KIR2DL4 (Shankarkumar et al., 2011).

ILT2 and ILT4 receptors are expressed on subclass of T, B, and NK cells and on monocytes, macrophages and dendritic cells however KIR2DL4 extraordinarily expressed on decidual NK cells, suggesting a delicate role in pregnancy (Strauss-Albee et al., 2014).

Activity of NK cells is controled by signals from activating and inhibitory receptors (Rebmann et al., 2014). Inhibitory receptors have a higher affinity toward $H L A-G$ than other $H L A$ class I molecules because of the much more avidity of disulfide dimers and trimers of $H L A-G$. Additionally, $H L A-G$ may exert long-time immunotolerogenic results through the generation of suppressor T cells (Agaugue et al., 2011). Or intercellular uptake of $H L A-G$ containing membrane patches (called trogocytosis) (Veit et al., 2012).

\section{Conclusion}

Successful pregnancy can be reached merely through a balanced dialog between mother and their fetus mediated by the placenta. Most genes associated with RM are involved in developing immunotolerance. A better understanding of $H L A-G$ and its proteins will provide new insights into the features of immunity and tolerance during pregnancy.

Recently published studies suggest that decreased or aberrant $H L A-G$ expression is related to some problems of pregnancy, such as preeclampsia, implantation failure during IVF, and risk of abortion. Moreover, these complications may be associated with $H L A-G$ polymorphism.

Discrepancy may also occur because of differences in study design, classification of RM, control groups, examination of only women experiencing RM instead of examination of couples or placenta, low statistical power because of the use of small sample sizes, ethnic differences in risk variations, and effects of environmental factors and life style on pregnancy outcomes.

\section{Competing Interests Statement}

The authors declare that there is no conflict of interests regarding the publication of this paper.

\section{References}

Abstracts for the 6th International Conference on HLA-G, July 2012, Paris, France. (2012). Tissue Antigens, 80(1), 78-103.

Afkhami, F., Khaniani, M. S., Farzadi, L., Paknejad, Z., \& Derakhshan, S. M. (2014). The HLA-G 14bp insertion/deletion polymorphism in Women with Recurrent Spontaneous Abortion. Iranian Journal of Allergy, Asthma and Immunology.

Agaugue, S., Carosella, E. D., \& Rouas-Freiss, N. (2011). Role of HLA-G in tumor escape through expansion of myeloid-derived suppressor cells and cytokinic balance in favor of Th2 versus Th1/Th17. Blood, 117(26), 7021-7031. http://dx.doi.org/10.1182/blood-2010-07-294389 
Alegre, E., Rizzo, R., Bortolotti, D., Fernandez-Landázuri, S., Fainardi, E., \& González, A. (2014). Some Basic Aspects of HLA-G Biology. Journal of Immunology Research. http://dx.doi.org/10.1155/2014/657625

Amodio, G., \& Gregori, S. (2012). Distinctive Immunological Functions of HLA-G. Histocompatibility, B. Abdel-Salam, (19), 38. http://dx.doi.org/10.5772/35248

Apps, R., Gardner, L., Sharkey, A. M., Holmes, N., \& Moffett, A. (2007). A homodimeric complex of HLA-G on normal trophoblast cells modulates antigen-presenting cells via LILRB1. Eur J Immunol, 37(7), 1924-1937. http://dx.doi.org/10.1002/eji.200737089

Apps, R., Sharkey, A., Gardner, L., Male, V., Kennedy, P., Masters, L., ... Moffett, A. (2011). Ex vivo functional responses to HLA-G differ between blood and decidual NK cells. Mol Hum Reprod, 17(9), 577-586. http://dx.doi.org/10.1093/molehr/gar022

Campbell, E. C., Antoniou, A. N., \& Powis, S. J. (2012). The multi-faceted nature of HLA class I dimer molecules. Immunology, 136(4), 380-384. http://dx.doi.org/10.1111/j.1365-2567.2012.03593.x

Carosella, E. D., Gregori, S., \& LeMaoult, J. (2011). The tolerogenic interplay(s) among HLA-G, myeloid APCs, and regulatory cells. Blood, 118(25), 6499-6505. http://dx.doi.org/10.1182/blood-2011-07-370742

Castelli, E. C., Mendes-Junior, C. T., Deghaide, N. H., de Albuquerque, R. S., Muniz, Y. C., Simoes, R. T., ... Donadi, E. A. (2010). The genetic structure of 3'untranslated region of the HLA-G gene: Polymorphisms and haplotypes. Genes Immun, 11(2), 134-141. http://dx.doi.org/10.1038/gene.2009.74

Castelli, E. C., Mendes-Junior, C. T., Veiga-Castelli, L. C., Roger, M., Moreau, P., \& Donadi, E. A. (2011). A comprehensive study of polymorphic sites along the HLA-G gene: Implication for gene regulation and evolution. Mol Biol Evol, 28(11), 3069-3086. http://dx.doi.org/10.1093/molbev/msr138

Donadi, E. A., Castelli, E. C., Arnaiz-Villena, A., Roger, M., Rey, D., \& Moreau, P. (2011). Implications of the polymorphism of HLA-G on its function, regulation, evolution and disease association. Cell Mol Life Sci, 68(3), 369-395. http://dx.doi.org/10.1007/s00018-010-0580-7

Enghelabifar, M., Allafan, S., Khayatzadeh, J., K. Abadi, K. S., Nazarabadi, M. H., Moradi, F., ... Mojarrad, M. (2014). Association of the maternal 14-bp insertion/deletion polymorphism in the histocompatibility leukocyte antigen G gene with recurrent implantation failure. Iran J Reprod Med, 12(9), 641-646.

Fan, W., Li, S., Huang, Z., \& Chen, Q. (2014). Relationship between HLA-G polymorphism and susceptibility to recurrent miscarriage: A meta-analysis of non-family-based studies. $J$ Assist Reprod Genet, 31(2), 173-184. http://dx.doi.org/10.1007/s10815-013-0155-2

Ford, H. B., \& Schust, D. J. (2009). Recurrent pregnancy loss: Etiology, diagnosis, and therapy. Rev Obstet Gynecol, 2(2), 76-83.

Foroni, I., Rita, A., Filipe, B., Santos, M., Lima, M., \& Bruges-Armas, J. (2014). HLA-E, HLA-F and HLA-G The Non-Classical Side of the MHC Cluster.

Haddad, R., Alves, D. C. C., Rocha-Junior, M. C., Azevedo, R., Pombo-de-Oliveira, M. D. S., Takayanagui, O. M., ... Kashima, S. (2011). HLA-G 14-bp insertion/deletion polymorphism is a risk factor for HTLV-1 infection. AIDS Res Hum Retroviruses, 27(3), 283-288. http://dx.doi.org/10.1089/aid.2010.0165

HLA-G (major histocompatibility complex, class I, G); Atlas Genet Cytogenet Oncol Haematol. Retrieved January 2012, from http://AtlasGeneticsOncology.org/Genes/HLAGID43744ch6p22.html

Holly, B., Ford, M., Danny, J., \& Schust, M. D. (2009). Recurrent Pregnancy Loss: Etiology, Diagnosis, and Therapy.

Hunt, J. S., \& Langat, D. L. (2009). HLA-G: A human pregnancy-related immunomodulator. Curr Opin Pharmacol, 9(4), 462-469. http://dx.doi.org/10.1016/j.coph.2009.05.007

Hunt, J. S., Petroff, M. G., McIntire, R. H., \& Ober, C. (2005). HLA-G and immune tolerance in pregnancy. FASEB J, 19(7), 681-693. http://dx.doi.org/10.1096/fj.04-2078rev

Hviid, T. V. (2006). HLA-G in human reproduction: Aspects of genetics, function and pregnancy complications. Hum Reprod Update, 12(3), 209-232. http://dx.doi.org/10.1093/humupd/dmi048

Hviid, T. V., Hylenius, S., Hoegh, A. M., Kruse, C., \& Christiansen, O. B. (2002). HLA-G polymorphisms in couples with recurrent spontaneous abortions. Tissue Antigens, 60(2), 122-132. http://dx.doi.org/10.1034/j. 1399-0039.2002.600202.x

Klitkou, L., Dahl, M., Hviid, T. V. F., Djurisic, S., Piosik, Z. M., Skovbo, P., ... Christiansen, O. B. (2015). 
Human leukocyte antigen (HLA)-G during pregnancy part I: Correlations between maternal soluble HLA-G at midterm, at term, and umbilical cord blood soluble HLA-G at term. Human Immunology, 76(4), 254-259. http://dx.doi.org/10.1016/j.humimm.2015.01.013

Kolte, A. M., Steffensen, R., Nielsen, H. S., Hviid, T. V., \& Christiansen, O. B. (2010). Study of the structure and impact of human leukocyte antigen (HLA)-G-A, HLA-G-B, and HLA-G-DRB1 haplotypes in families with recurrent miscarriage. Hum Immunol, 71(5), 482-488. http://dx.doi.org/10.1016/j.humimm.2010.02.001

Larsen, E. C., Christiansen, O. B., Kolte, A. M., \& Macklon, N. (2013). New insights into mechanisms behind miscarriage. BMC medicine, 11(1), 154. http://dx.doi.org/10.1186/1741-7015-11-154

Larsen, M. H., Bzorek, M., Pass, M. B., Larsen, L. G., Nielsen, M. W., Svendsen, S. G., .. Hviid, T. V. (2011). Human leukocyte antigen-G in the male reproductive system and in seminal plasma. Mol Hum Reprod, 17(12), 727-738. http://dx.doi.org/10.1093/molehr/gar052

Lynge Nilsson, L., Djurisic, S., \& Hviid, T. V. (2014). Controlling the Immunological Crosstalk during Conception and Pregnancy: HLA-G in Reproduction. Front Immunol, 5, 198. http://dx.doi.org/10.3389/ fimmu.2014.00198

Mallia, J. V., Das, D. K., \& Maitra, A. (2012). Role of HLA in human pregnancy. Int J Hum Genet, 12(1), 33-36.

Martelli-Palomino, G., Pancotto, J. A., Muniz, Y. C., Mendes-Junior, C. T., Castelli, E. C., Massaro, J. D., ... Donadi, E. A. (2013). Polymorphic sites at the 3' untranslated region of the HLA-G gene are associated with differential $H L A-G$ soluble levels in the Brazilian and French population. PLoS One, 8(10), e71742. http://dx.doi.org/10.1371/journal.pone.0071742

Matter, T. F., \& Sharif, F. A. (2013). HLA-G and HLA-E Gene polymorphisms in idiopathic recurrent spontaneous abortion women in Gaza strip-Palestine. Int $J$ Reprod Contracept Obstet Gynecol, 2(3), 277-283. http://dx.doi.org/10.5455/2320-1770.ijrcog20130904

Moreau, P., Flajollet, S., \& Carosella, E. D. (2009). Non-classical transcriptional regulation of HLA-G: An update. Journal of Cellular and Molecular Medicine, 13(9b), 2973-2989. http://dx.doi.org/10.1111/j. 1582-4934.2009.00800.x

Picard, C., Cristofaro, J. D., Azzouz, D. F., Kanaan, S. B., Roudier, J., \& Lambert, N. C. (2013). Analyzing HLA-G polymorphisms in children from women with scleroderma. Hum Immunol, 74(4), 468-472. http://dx.doi.org/10.1016/j.humimm.2012.11.030

Rebmann, V., Nardi, F. D. S., Wagner, B., \& Horn, P. A. (2014). HLA-G as a tolerogenic molecule in transplantation and pregnancy. J Immunol Res, 297073. http://dx.doi.org/10.1155/2014/297073

Rico-Rosillo, M. G., \& Vega-Robledo, G. B. (2012). Immunological mechanisms involved in pregnancy. Ginecol Obstet Mex, 80(5), 332-340.

Shankarkumar, U., Shankarkumar, A., Chedda, Z., \& Ghosh, K. (2011). Role of 14-bp deletion/insertion polymorphism in exon 8 of the HLA-G gene in recurrent spontaneous abortion patients. J Hum Reprod Sci, 4(3), 143-146. http://dx.doi.org/10.4103/0974-1208.92289

Sipak-Szmigiel, O., Cybulski, C., Lubinski, J., \& Ronin-Walknowska, E. (2008). HLA-G polymorphism in a Polish population and reproductive failure. Tissue Antigens, 71(1), 67-71.

Strauss-Albee, D. M., Horowitz, A., Parham, P., \& Blish, C. A. (2014). Coordinated regulation of NK receptor expression in the maturing human immune system. $J$ Immunol, 193(10), 4871-4879. http://dx.doi.org/10. 4049/jimmunol.1401821

Torres, M. I., Luque, J., Lorite, P., Isla-Tejera, B., Palomeque, T., Aumente, M. D., ... Pena, J. (2009). 14-Base pair polymorphism of human leukocyte antigen-G as genetic determinant in heart transplantation and cyclosporine therapy monitoring. Hum Immunol, 70(10), 830-835. http://dx.doi.org/10.1016/j.humimm. 2009.07.012

Tripathi, P., Abbas, A., Naik, S., \& Agrawal, S. (2004). Role of 14-bp deletion in the HLA-G gene in the maintenance of pregnancy. Tissue Antigens, 64(6), 706-710. http://dx.doi.org/10.1111/j.1399-0039.2004. 00308.x

Veit, T. D., \& Chies, J. A. (2009). Tolerance versus immune response microRNAs as important elements in the regulation of the HLA-G gene expression. Transpl Immunol, 20(4), 229-231. http://dx.doi.org/10. 1016/j.trim.2008.11.001 
Veit, T. D., Cazarolli, J., Salzano, F. M., Schiengold, M., \& Chies, J. A. (2012). New evidence for balancing selection at the HLA-G locus in South Amerindians. Genet Mol Biol, 35(4 (suppl)), 919-923. http://dx.doi.org/10.1590/S1415-47572012000600005

Veit, T. D., Vianna, P., \& Chies, J. A. B. (2010). HLA-G-From fetal tolerance to a regulatory molecule in inflammatory diseases. Current Immunology Reviews, 6(1), 1-15. http://dx.doi.org/10.2174/15733955 11006010001

Verloes, A., Van de Velde, H., LeMaoult, J., Mateizel, I., Cauffman, G., Horn, P. A., ... Vercammen, M. (2011). HLA-G expression in human embryonic stem cells and preimplantation embryos. J Immunol, 186(4), 2663-2671. http://dx.doi.org/10.4049/jimmunol.1001081

Wang, X., Li, B., Wang, J., Lei, J., Liu, C., Ma, Y., \& Zhao, H. (2012). Evidence that miR-133a cause's recurrent spontaneous abortion by reducing HLA-G expression. Reprod Biomed Online, 25(4), 415-424. http://dx.doi.org/10.1016/j.rbmo.2012.06.022

Warner, C. M., Lampton, P. W., Newmark, J. A., \& Cohen, J. (2008). Symposium: Innovative techniques in human embryo viability assessment. Soluble human leukocyte antigen-G and pregnancy success. Reprod Biomed Online, 17(4), 470-485. http://dx.doi.org/10.1016/S1472-6483(10)60233-7

Xue, S., Yang, J., Yao, F., Xu, L., \& Fan, L. (2007). Recurrent spontaneous abortions patients have more-14 $\mathrm{bp} /+14 \mathrm{bp}$ heterozygotes in the 3'UT region of the HLA-G gene in a Chinese Han population. Tissue Antigens, 69(Suppl 1), 153-155. http://dx.doi.org/10.1111/j.1399-0039.2006.763_7.x

Yan, W. H., Lin, A., Chen, X. J., Dai, M. Z., Gan, L. H., Zhou, M. Y., .. Liu, J. M. (2006). Association of the maternal 14-bp insertion polymorphism in the HLA-G gene in women with recurrent spontaneous abortions. Tissue Antigens, 68(6), 521-523. http://dx.doi.org/10.1111/j.1399-0039.2006.00723.x

Zhao, Y. M., Zheng, M. L., Zhang, G. L., Zhang, Y. L., Hua, A. L., \& He, J. M. (2009). Related study between Serum levels of sHLA-G, HLA-G14bp insertion/deletion polymorphism and recurrent spontaneous abortion. Shanxi Med J, 38, 390-391.

\section{Copyrights}

Copyright for this article is retained by the author(s), with first publication rights granted to the journal.

This is an open-access article distributed under the terms and conditions of the Creative Commons Attribution license (http://creativecommons.org/licenses/by/3.0/). 